\title{
Quality Assessment of Systematic Reviews of Temporomandibular Joint Ankylosis Surgical Treatment Outcomes
}

\author{
Vivekanand S Kattimani ${ }^{1}$, Abhishek Jairaj ${ }^{2}$, Nikhil O Govindan ${ }^{3}$, Paul Mathai ${ }^{4}$, Swati Sahu ${ }^{5}$, Abhishek Patley ${ }^{6}$, Parveen S Sultana ${ }^{7}$
}

\begin{abstract}
Aim: Temporomandibular joint ankylosis (TMJA) management involves many surgical treatment modalities depending on the experience of the operator. A lot of literature has been published on various treatment modalities. Many systematic reviews (SRs) were published without any published prior protocol. So, the study aimed to evaluate the quality of SRs with meta-analysis of TMJA management.

Materials and methods: Systematic reviews with meta-analysis were included for the quality assessment using AMSTAR (assessment of multiple SRs) and Glenny et al. checklist by two independent teams. The search was limited to the Medline database archival (from January 1980 to December 2018).

Results: The primary search identified 1,507 related articles. After activation of different filters, abstracts screening, and cross-referencing, finally, a total of six studies were assessed to make the overview up-to-date.

Conclusion: The articles scored 8 to 11 with AMSTAR and 7 to 13 with the Glenny et al. checklist. None of the published reviews received maximum scores. The methodology and heterogeneity are essential factors to assess the quality of the published literature.

Clinical significance: None of the included meta-analysis was registered or published protocol with Prospero or Cochrane before publication for better validity of the studies. The authors are advised to follow reporting criteria so that in the future it is possible to provide the standards of care for TMJA with the highest quality of evidence.

Keywords: Condyle, Cranium, Diarthrodial joint, Evidenced-based dentistry, Systematic review.

The Journal of Contemporary Dental Practice (2020): 10.5005/jp-journals-10024-2766
\end{abstract}

\section{INTRODUCTION}

Clinical decision making for the treatment approach in dentistry or medicine depends on evidence, published in peer-reviewed journals. ${ }^{1-3}$ The decision for the standard of care for any treatment and recommendation depends on remarks of systematic reviews (SRs), randomized-controlled trials (RCTs), cohort studies, and least with retrospective studies. ${ }^{4}$ For few entities like temporomandibular joint ankylosis (TMJA), it is difficult to find RCTs because of less number of patients with similar clinical presentation, availability of many surgical modalities, and varied clinical scenario of ankylosis. So, it is difficult to ascertain and recommend a single modality of treatment or standardization of methodology. Because of these prevailing factors, the clinician will be in a dilemma during the selection of treatment modality. ${ }^{5}$ In recent years different protocols were developed, modified for the management of ankylosis. ${ }^{6,7}$ Thousands of articles were published regarding the management of TMJA. But this evidence is questionable because of varying methodologies and difficulty in reproducibility as ankylosis management and prognosis are multifactorial. So, biomedical journals started following standard publishing guidelines to maintain uniformity while reporting. ${ }^{8}$

In recent past, publishers adopted various reporting guidelines like CONSORT (Consolidated Standards of Reporting Trials), STROBE (STrengthening the Reporting of OBservational studies in Epidemiology), SPIRIT (standard protocol items for clinical trials), SQQR (standards for reporting qualitative research), etc., for various types of article publications. ${ }^{8}$ These guidelines help clinicians to prevent publication bias. Multiple tools were also developed to
${ }^{1}$ Department of Oral and Maxillofacial Surgery, Sibar Institute of Dental Sciences, Guntur, Andhra Pradesh, India

${ }^{2}$ Faculty of Dentistry, AIMST University, Jalan Bedong-Semeling Bedong Kedah, Malaysia

${ }^{3}$ Department of Oral and Maxillofacial Surgery, Sree Anjaneya Institute of Dental Sciences, Modakkalloor, Calicut, Kerala, India

${ }^{4}$ Department of Oral and Maxillofacial Surgery and Dentistry, Jubilee Mission Medical College Hospital and Research Institute, Thrissur, Kerala, India

5,6Department of Oral and Maxillofacial Surgery, New Horizon Dental College and Research Institute, Bilaspur, Chhattisgarh, India

${ }^{7}$ Department of Public Health Dentistry, Sibar Institute of Dental Sciences, Guntur, Andhra Pradesh, India

Corresponding Author: Vivekanand S Kattimani, Department of Oral and Maxillofacial Surgery, Sibar Institute of Dental Sciences, Guntur, Andhra Pradesh, India, Phone: +91 9912400988, e-mail: drvivekanandsk@gmail.com

How to cite this article: Kattimani VS, Jairaj A, Govindan NO, et al. Quality Assessment of Systematic Reviews of Temporomandibular Joint Ankylosis Surgical Treatment Outcomes. J Contemp Dent Pract 2020;21(3):337-349.

Source of support: Nil

Conflict of interest: None

critically analyze the methodological quality of SRs and provide the recommendations based on the highest evidence. ${ }^{9-12}$

(c) The Author(s). 2020 Open Access This article is distributed under the terms of the Creative Commons Attribution 4.0 International License (https://creativecommons. org/licenses/by-nc/4.0/), which permits unrestricted use, distribution, and non-commercial reproduction in any medium, provided you give appropriate credit to the original author(s) and the source, provide a link to the Creative Commons license, and indicate if changes were made. The Creative Commons Public Domain Dedication waiver (http://creativecommons.org/publicdomain/zero/1.0/) applies to the data made available in this article, unless otherwise stated. 
The available SRs showed that only $40.5 \%$ of the studies assessed the risk of bias/quality. ${ }^{3}$ Till date, quality assessment of the published reviews on TMJA had not been performed. ${ }^{2,13}$ In the wake of this diversity, the overview of SR articles with meta-analysis (MA) regarding comparative surgical treatment outcomes of TMJA was planned to assess and compare the quality using two types of tools: AMSTAR $^{9}$ (assessment of multiple SRs) and the Glenny ${ }^{10}$ checklist.

\section{Materials and Methods}

An electronic search was performed with the date and no language restriction. The search included articles published from January 1980 to December 2018 using various Boolean operators with multiple combinations of search strings in the Medline database. Depending on the title, abstract and full-text articles published in the English language were selected for reading with the following selection criteria to ascertain the objective. Only published articles of TMJA surgical treatment outcomes SR with MA were included for assessment. After initial screening, full-text articles were selected for critical reading and analysis. The authors were contacted for further clarification if the ambiguity in the published data exists. Two independent teams assessed the quality of included studies using AMSTAR ${ }^{9}$ and the Glenny et al. ${ }^{10}$ checklist.

The scoring was performed according to the characteristics of the study for a quality check as per the checklist. These criteria were based on the questions framed by $\operatorname{AMSTAR}^{9}$ and Glenny et al. ${ }^{10}$ for the assessment of quality check of published SR and MA. These questions assess how well the SR and MA were performed to reach the consensus on the treatment outcomes depending on the objectives of the study. The AMSTAR ${ }^{9}$ checklist consists of 11 questions, whereas the Glenny et al. ${ }^{10}$ list consists of 14 questions to assess quality. These questions/evaluative factors assess search criteria, methodology, the prior publication of the protocol, the validity of statistics of included studies, consideration of bias factors, any missing data, method of data collection, scientific quality, heterogeneity, and conclusive remarks based on the rationale supported by outcomes of the included primary studies. Differences in scoring among the two teams sorted with discussion. The methodological quality and statistics was assessed by a team of review members involving a public health dentist. The following search criteria with MeSH words were applied to generate the required data from the Medline archival.

\section{Search Criteria and Data Screening}

A literature search was performed using four search categories, which included various Boolean operators and MeSH keywords related to treatment outcomes of surgical management of TMJ ankylosis (Table $\mathrm{S} 1$ supplementary material).

\section{Statistical Analysis}

The data were collected using both quality assessment tools and were analyzed using descriptive statistics. The Spearman correlation test was performed for determining correlation between the two scoring criteria.

\section{Results}

After going through the abstract of all final results of four search categories (Table S1) and narrowing down the search to address the objective of quality assessment, authors found 10 publications (Flowchart 1). After going through full-length articles, out of ten, one
Flowchart 1: Screening and selection process

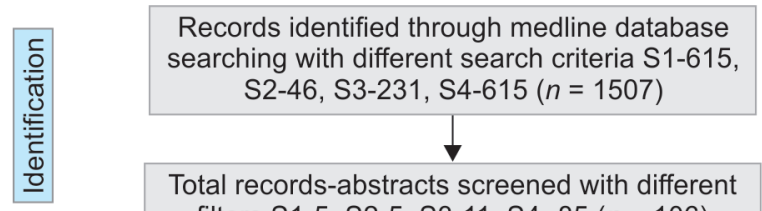
filters S1-5, S2-5, S3-11, S4- $85(n=106)$

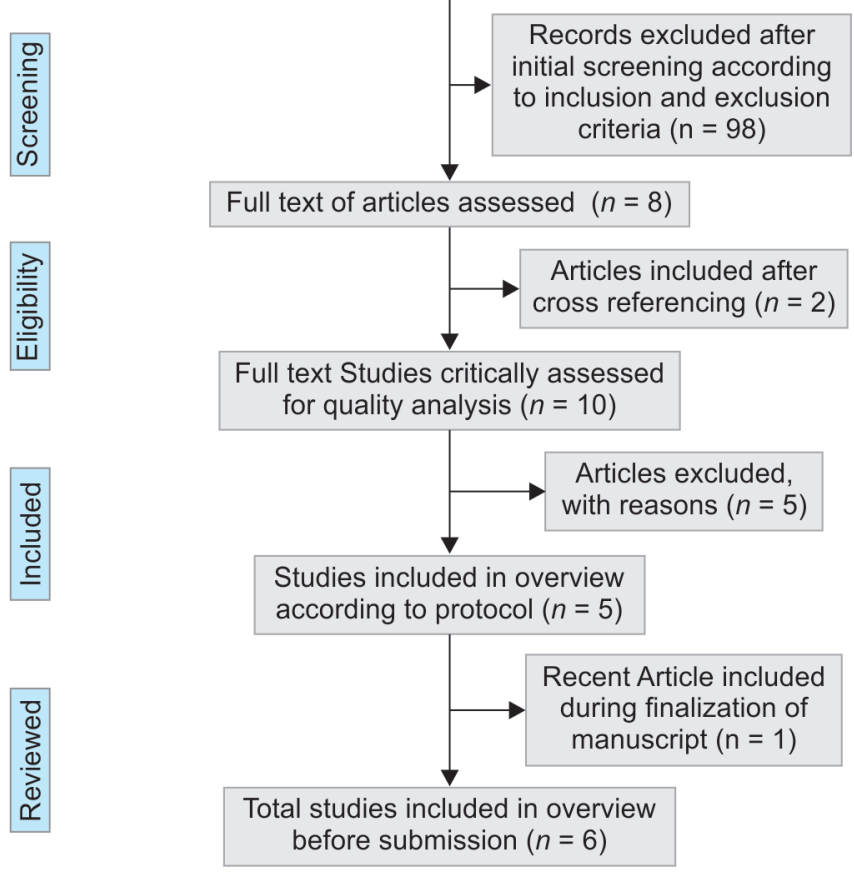

Table 1: List of excluded studies and the reason for their exclusion

\begin{tabular}{ll}
\hline Author and year & Reason for exclusion \\
\hline Sporniak-Tutak et al. ${ }^{14}(2011)$ & Descriptive review \\
Movahed and Mercuri ${ }^{15}(2015)$ & Descriptive review \\
Sharma et al. ${ }^{16}(2017)$ & $\begin{array}{l}\text { Descriptive review } \\
\text { Bénateau et al. }{ }^{17}(2016)\end{array}$ \\
$\begin{array}{l}\text { Other than the English language } \\
\text { (in French) }\end{array}$ \\
AAOMS ParCare ${ }^{18}$ (2012) & $\begin{array}{l}\text { Not focused exclusively on } \\
\text { comparative TMJ surgeries }\end{array}$ \\
\hline
\end{tabular}

was in the French language, another was American Association of Oral and Maxillofacial Surgeons (AAOMS) guidelines not focused on comparisons, and three were descriptive reviews focused mainly on the effects of various surgical treatment modalities in ankylosis without MA (Table 1). ${ }^{14-18}$ Five studies were found eligible for the review, but our team found one more recently published study, ${ }^{5}$ which has been added for final assessment to make an effort more complete and up-to-date and which rose the total number of included studies to six.

\section{Study Characteristics}

The scoring for included studies is presented in Table 2 (other characteristics continued in Tables S2 and S3 as supplementary material). Katsnelson ${ }^{19}$ included four studies ${ }^{20-23}$ searched between 1966 and May 2010. Al-Moraissi et al. ${ }^{24}$ included 16 publications ${ }^{20-23,25-36}$ (nine retrospective studies and seven controlled clinical trials) searched in December 2013 without date restrictions. Ma et al. ${ }^{37}$ included eight retrospective cohort studies 
Table 2: Main characteristics and quality assessment scores obtained using AMSTAR and Glenny et al. checklist

\begin{tabular}{|c|c|c|c|c|c|}
\hline Authors & $\begin{array}{l}\text { Reference } \\
\text { number }\end{array}$ & $\begin{array}{l}\text { No. of studies } \\
\text { included }\end{array}$ & Outcome measures & $\begin{array}{l}\text { AMSTAR score (lowest } \\
0, \text { highest 11) }\end{array}$ & $\begin{array}{l}\text { Checklist of Glenny et al. } \\
\text { (lowest } 0 \text {, highest 14) }\end{array}$ \\
\hline Katsnelson & 19 & 4 & Maximal inter-incisal opening & 8 & 7 \\
\hline Al-Moraissi & 24 & 16 & Maximal inter-incisal opening & 11 & 10 \\
\hline Ma et al. & 37 & 8 & $\begin{array}{l}\text { Maximal inter-incisal opening and } \\
\text { incidence of reankylosis }\end{array}$ & 11 & 12 \\
\hline Ma et al. & 38 & 8 & $\begin{array}{l}\text { Maximal inter-incisal opening and } \\
\text { incidence of reankylosis }\end{array}$ & 11 & 13 \\
\hline De Roo et al. & 41 & 38 & Maximal inter-incisal opening & 11 & 11 \\
\hline Mittal et al. & 5 & 26 & $\begin{array}{l}\text { Incidence of reankylosis and maximal } \\
\text { inter-incisal opening }\end{array}$ & 11 & 11 \\
\hline
\end{tabular}

Table 3: AMSTAR checklist and the number of studies that satisfied each of the criteria

\begin{tabular}{|c|c|c|c|c|c|c|c|}
\hline S. no. & AMSTAR questions & Katsnelson ${ }^{19}$ & Al-Moraissi et al. ${ }^{24}$ & Ma et al. ${ }^{37}$ & Ma et al. ${ }^{38}$ & De Roo et al. ${ }^{41}$ & Mittal et al. ${ }^{5}$ \\
\hline 1 & $\begin{array}{l}\text { Was an a priori design } \\
\text { provided? }\end{array}$ & Yes & Yes & Yes & Yes & Yes & Yes \\
\hline 2 & $\begin{array}{l}\text { Is there a duplicate } \\
\text { study selection and data } \\
\text { extraction? }\end{array}$ & Yes & Yes & Yes & Yes & Yes & Yes \\
\hline 3 & $\begin{array}{l}\text { Was a comprehensive } \\
\text { literature search } \\
\text { performed? }\end{array}$ & Yes & Yes & Yes & Yes & Yes & Yes \\
\hline 4 & $\begin{array}{l}\text { Was the status of the } \\
\text { publication (i.e., grey } \\
\text { literature) used as an } \\
\text { inclusion criterion? }\end{array}$ & $\begin{array}{l}\text { Yes, no mention } \\
\text { of grey } \\
\text { literature }\end{array}$ & $\begin{array}{l}\text { Yes, no mention } \\
\text { of grey literature }\end{array}$ & $\begin{array}{l}\text { Yes, no mention } \\
\text { of grey } \\
\text { literature }\end{array}$ & $\begin{array}{l}\text { Yes, no mention } \\
\text { of grey } \\
\text { literature }\end{array}$ & $\begin{array}{l}\text { Yes, no mention } \\
\text { of grey } \\
\text { literature }\end{array}$ & $\begin{array}{l}\text { Yes, no mention } \\
\text { of grey } \\
\text { literature }\end{array}$ \\
\hline 5 & $\begin{array}{l}\text { Was a list of studies } \\
\text { (included and excluded) } \\
\text { provided? }\end{array}$ & No & Yes & Yes & $\begin{array}{l}\text { Yes, but no list } \\
\text { of excluded } \\
\text { studies }\end{array}$ & $\begin{array}{l}\text { Yes, but no } \\
\text { record of ex- } \\
\text { cluded studies }\end{array}$ & Yes \\
\hline 6 & $\begin{array}{l}\text { Were the characteristics } \\
\text { of the included studies } \\
\text { provided? }\end{array}$ & Yes & Yes & Yes & Yes & Yes & Yes \\
\hline 7 & $\begin{array}{l}\text { Was the scientific } \\
\text { quality of the included } \\
\text { studies assessed and } \\
\text { documented? }\end{array}$ & No & Yes & Yes & Yes & Yes & Yes \\
\hline 8 & $\begin{array}{l}\text { Was the scientific quality } \\
\text { of the included studies } \\
\text { used appropriately } \\
\text { in formulating } \\
\text { conclusions? }\end{array}$ & Yes & Yes & Yes & Yes & $\begin{array}{l}\text { Yes, using a } \\
\text { customized } \\
\text { framework }\end{array}$ & Yes \\
\hline 9 & $\begin{array}{l}\text { Were the methods used } \\
\text { to combine the findings } \\
\text { of studies appropriate? }\end{array}$ & Yes & Yes & Yes & Yes & Yes & Yes \\
\hline 10 & $\begin{array}{l}\text { Was the likelihood } \\
\text { of publication bias } \\
\text { assessed? }\end{array}$ & Yes & Yes & Yes & Yes & Yes & Yes \\
\hline 11 & $\begin{array}{l}\text { Was the conflict of } \\
\text { interest stated? }\end{array}$ & No & Yes & Yes & Yes & Yes & Yes \\
\hline
\end{tabular}

and were searched up to October 11, 2014. Ma et al. ${ }^{38}$ published one more study that included eight studies ${ }^{23,26,28,30,31,36,39,40}$ searched between 1946 and July 28, 2014. De Roo et al. ${ }^{41}$ publication included 38 studies $^{21-23,28,31,42-73}$ with four prospective and one RCT, and other study types were not mentioned. Mittal et al. ${ }^{5}$ included 26 studies $^{20-23,26-28,30-32,34,39,40,48,53,66,72,74-82}$ for MA.

\section{Quality Assessment}

None of the published reviews included in this overview met all the AMSTAR criteria (Table 3 ). The scores ranged from 8 points to
11 points. Point 4 of the AMSTAR guideline was partly explained in all publications. One study ${ }^{19}$ received the lowest score indicating poorly performed study involving four articles for review and MA, whereas the other publications $s^{5,24,37,38,41}$ received a score of 11. Two of the MA were published in the same year by the same author with different objectives involving eight studies each for MA. ${ }^{37,38}$

The scores for the Glenny et al. ${ }^{10}$ checklist varied between 7 points and 13 points (Table 4). Spearman's correlation was positive between the scores of two quality assessment tools, with a coefficient of 0.66 ( $p=0.15$ ) (Fig. 1). The mean and SD score for 
Table 4: Checklist of Glenny et al. and the number of studies that satisfied each of the criteria

\begin{tabular}{|c|c|c|c|c|c|c|c|}
\hline S. no. & Glenny et al. questions & Katsnelson ${ }^{19}$ & $\begin{array}{l}\text { Al-Moraissi et } \\
\text { al. }^{24}\end{array}$ & Ma et al. ${ }^{37}$ & Ma et al. ${ }^{38}$ & De Roo et al. ${ }^{41}$ & Mittal et al. ${ }^{5}$ \\
\hline 1 & $\begin{array}{l}\text { Did the reviewer address a } \\
\text { focused question? }\end{array}$ & Yes & Yes & Yes & Yes & Yes & Yes \\
\hline 2 & $\begin{array}{l}\text { Did the authors look for } \\
\text { appropriate papers? }\end{array}$ & Yes & Yes & Yes & Yes & Yes & Yes \\
\hline 3 & $\begin{array}{l}\text { Did the authors attempt } \\
\text { to identify all relevant } \\
\text { studies? }\end{array}$ & Yes & Yes & Yes & Yes & Yes & Yes \\
\hline 4 & $\begin{array}{l}\text { Did the authors search } \\
\text { for published and } \\
\text { unpublished literature? }\end{array}$ & $\begin{array}{l}\text { Unpublished } \\
\text { not mentioned }\end{array}$ & $\begin{array}{l}\text { Unpublished } \\
\text { not mentioned }\end{array}$ & $\begin{array}{l}\text { Unpublished } \\
\text { not mentioned }\end{array}$ & $\begin{array}{l}\text { Unpublished } \\
\text { not mentioned }\end{array}$ & $\begin{array}{l}\text { Unpublished } \\
\text { not mentioned }\end{array}$ & $\begin{array}{l}\text { Unpublished } \\
\text { not mentioned }\end{array}$ \\
\hline 5 & $\begin{array}{l}\text { Were all languages } \\
\text { considered? }\end{array}$ & Not mentioned & Yes & Not mentioned & Yes & Yes & Not mentioned \\
\hline 6 & $\begin{array}{l}\text { Was any hand-searching } \\
\text { carried out? }\end{array}$ & Yes & Yes & Yes & Yes & Yes & Yes \\
\hline 7 & $\begin{array}{l}\text { Was it stated that at least } \\
\text { two reviewers applied the } \\
\text { inclusion criteria? }\end{array}$ & $\begin{array}{l}\text { No, one author } \\
\text { performed }\end{array}$ & Not mentioned & Yes & Yes & Yes & Yes \\
\hline 8 & $\begin{array}{l}\text { Did reviewers attempt to } \\
\text { assess the quality of the } \\
\text { included studies? }\end{array}$ & $\begin{array}{l}\text { Partly } \\
\text { assessed using } \\
\text { publication } \\
\text { bias }\end{array}$ & Assessed & Yes & Yes & Yes & Yes \\
\hline 9 & $\begin{array}{l}\text { If so, did they include this } \\
\text { quality assessment in the } \\
\text { analysis? }\end{array}$ & $\begin{array}{l}\text { No, only } \\
\text { publication } \\
\text { bias assessed }\end{array}$ & Yes & Yes & Yes & No & Yes \\
\hline 10 & $\begin{array}{l}\text { Was it stated that the } \\
\text { quality assessment was } \\
\text { carried out by at least two } \\
\text { reviewers? }\end{array}$ & No & No & Yes & Yes & No & Not mentioned \\
\hline 11 & $\begin{array}{l}\text { If the results have } \\
\text { been combined, was it } \\
\text { reasonable to do so? }\end{array}$ & Yes & Yes & Yes & Yes & Yes & Yes \\
\hline 12 & $\begin{array}{l}\text { Are the results clearly } \\
\text { displayed? }\end{array}$ & Yes & Yes & Yes & Yes & Yes & Yes \\
\hline 13 & $\begin{array}{l}\text { Was an assessment of } \\
\text { heterogeneity made, and } \\
\text { were reasons for variation } \\
\text { discussed? }\end{array}$ & No & Yes & Yes & Yes & Yes & Yes \\
\hline 14 & $\begin{array}{l}\text { Were the results of } \\
\text { the review interpreted } \\
\text { appropriately? }\end{array}$ & Yes & Yes & Yes & Yes & Yes & Yes \\
\hline
\end{tabular}

AMSTAR was $10.50 \pm 1.22$ and for Glenny et al. was $10.67 \pm 2.06$ (Table S4 supplementary material).

\section{Discussion}

This overview is limited to SRs with a MA that evaluated the various surgical techniques used in the management of TMJA and its outcomes in humans. The TMJA prognosis is multifactorial; to date, no consensus on the standards of care has been advised. It might be attributed to patient and clinician factors broadly. Many attempts have been made in the past to assess the published literature. 5, 19,24,37,38,41 Few SRs are published with and without MA. $5,14,15,19,24,37,38,41$ Surprisingly, it was noted that variations in the number of included studies despite almost the same outcomes are being evaluated and published in the same year and same journal. ${ }^{37,41}$ This variation might be attributed to the inclusion and exclusion criteria. Despite the increased number of publications, the quality of the publications has not reached the highest scoring.

The recent study ${ }^{5}$ is published after a gap of 4 years from the last published literature, ${ }^{41}$ but it includes a lesser number of studies compared to the previous research for interpretation even though the scope has been broadened by adding the distraction osteogenesis. ${ }^{5}$ The lack of inclusiveness of the previous MA (Ma et al., 2015 ${ }^{37,38}$ ) in discussion indicates methodological flaws in the search criteria. ${ }^{41}$ So, a more rigorous researching and reviewing approach is necessary for better evidence and conclusive remarks. The authors have not found the Prospero/Cochrane protocol for the published studies included in this overview. The SRs with or without MA should register its protocol in Prospero or Cochrane systemic protocol reviews for validity, which in turn prevents duplication of studies and methodological flaws. Leaving apart the Kabans protocol, the existing literature is unable to draw any further 


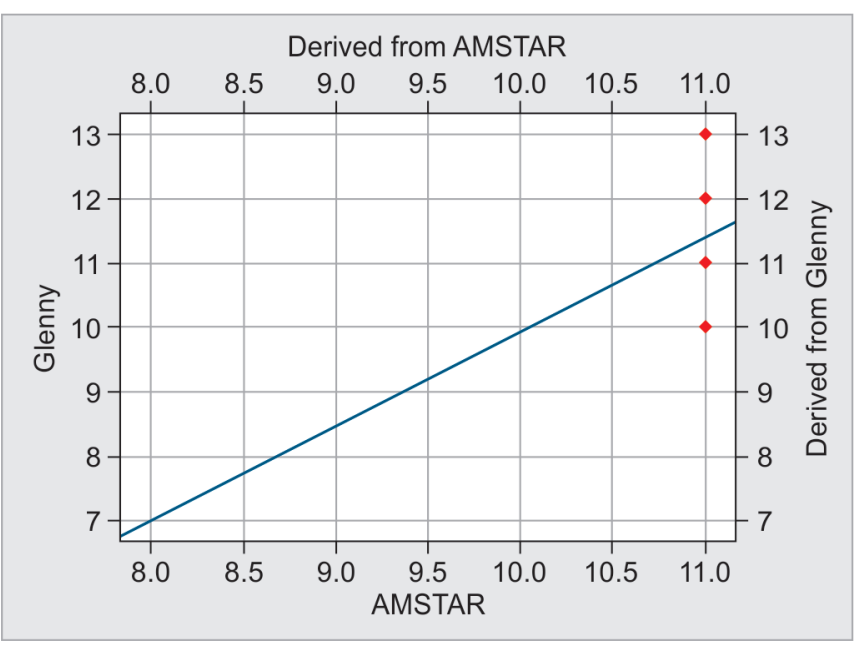

Fig. 1: Correlation between AMSTAR and Glenny et al. scores

conclusive remarks. ${ }^{6,7}$ So, the readers should exercise caution while adopting the interpretation and conclusive remarks.

The increase in scoring indicates an improvement in the reporting pattern from the first $\mathrm{MA}^{19}$ (the year 2012) to the latest published ${ }^{5}$ (the year 2019). The number of published articles were increased because of the shift of the thought process from gap arthroplasty to interposition arthroplasty and reconstruction arthroplasty using various techniques that have widened the scope of the study. $5,19,24,37,38,41$ This paradigm shift in surgical management made the prognosis better with reduced postoperative complications and improved patient compliance, function, and aesthetics. The reporting quality of RCT, controlled clinical trail (CCT), or case series needs to be improved for better evidence. ${ }^{83}$ None of the published studies reported TMJA classification before intervention, so it might have given a better edge for correlation of the surgical method and prognosis. Although the publications reviewed had similar objectives in this overview, but they had high methodological heterogeneity. However, these SRs did not meet all of the criteria of the checklists used, indicating potential publication bias.

The risk of bias assessment is essential for individual studies. ${ }^{83}$ Adopting the Grading of Recommendations Assessment, Development, and Evaluation (GRADE) approach for the synthesis of evidence would be a significant step for improving the quality of clinical evidence..$^{83}$ The International Committee of Medical Journal Editors (ICMJE) ${ }^{84}$ set many reporting guidelines for human clinical series or CCT or RCT publications. If authors adhere strictly to these reporting criteria, then better evidence can be provided, which can be universally adopted for developing the TMJA treatment protocol. High-quality reviews may help the clinicians and patients to have the best possible results. ${ }^{83}$ The publication bias assessment and homogeneity are fundamental for the studies considered in MA. ${ }^{2,3}$ These factors clarify the reader the methodological quality opted for the same. Quality assessments, such as the Cochrane Collaboration's tool for assessing the risk of bias for RCTs and Newcastle-Ottawa Quality Assessment Scale for cohort studies, were used in the included studies.

The TMJA surgical management outcome analysis consists of several confounding factors. Some of them should be included in inclusion or exclusion criteria so that the effect can be minimized.
The time duration of ankylosis, type, age, treatment provided, postsurgical monitoring, etc., are important factors along with the surgical expertise of the clinicians for the better outcome. Even though the study included extensive quality checks using checklists but these lists lack of quantitative assessment. In our study, the lowest score obtained was 7. Despite the lack of standard reference scale for discrimination as poor or good study, the score below 3 was considered as poorly designed. ${ }^{4,85}$ But in our overview, we found moderate scored reviews.

The checklists used in this overview are more comprehensive and were used extensively with validation for the quality checks. Many other tools are available but are not so comprehensive and not provide scoring. ${ }^{9,11,12,86-88}$ Because of the scoring, it is possible to correlate using Spearman's correlation, which measures the relationship between two variables. So, we have used these two checklists. In this study, the scores were positively correlated, indicating a lower possibility of errors and a lower risk of bias in the scoring system implemented.

The study has limited the critical assessment to the English language literature archived in the Medline database for the accuracy, reproducibility, and quality of publications for evaluation. The increase in predatory journal publications is worrying some for the evidence published, and the involvement of such studies as reference might mislead the outcome or recommendation..$^{13,84}$

\section{Conclusion}

The clinicians and researchers, as a result of this, advised to look after the reporting guidelines and adhere to the protocol of reviews for better evidence. Authors cautioned to refer the valid, researchable, and indexed journals for better validity as few of the MA referenced predatory journals in their research, which may undermine the objective of SR and MA. The word of caution is always better for better evidence creation for the future generation and the standard of care.

\section{Author Contributions}

Vivekanand S Kattimani and Abhishek Jairaj drafted the protocol; Vivekanand S Kattiman, Abhishek Jairaj, and Shaik Parveen Sultana developed a search strategy. Team 1, Vivekanand S Kattimani, Abhishek Jairaj, Shaik Parveen Sultana, and Team 2, Nikhil O Govindan, Paul Mathai, Swati Sahu, Abhishek Patley, searched for literature. Vivekanand S Kattimani, Abhishek Jairaj, and Swati Sahu selected articles to include in this analysis. Paul Mathai and Abhishek Patley obtained copies of publications of all included studies. Vivekanand S Kattimani, Nikhil O Govindan and Swati Sahu extracted data from publications. Abhishek Jairaj and Shaik Parveen Sultana verified the data entered for analysis. Shaik Parveen Sultana carried out the analysis part. Vivekanand S Kattimani, Abhishek Jairaj, and Shaik Parveen Sultana interpreted the analysis; Vivekanand S Kattimani and Abhishek Jairaj drafted the final review. All the authors read and approved the final version.

\section{Ethical Approval}

Not required, as it does not involve humans or animals in the study.

\section{Acknowledgments}

All authors have viewed and agreed to the submission. 


\section{References}

1. Am G, Esposito M, Coulthard P, et al. Evidence-based dentistry: the assessment of systematic reviews in dentistry. Br Dent $J$ 2003;195(2):83-83. DOI: 10.1038/sj.bdj.4810332.

2. El-rabbany M, Li S, Bui S, et al. A quality analysis of systematic reviews in Dentistry, part 1: meta-Analyses of randomized controlled trials. J Evid Based Dent Pract 2017. DOI: 10.1016/j.jebdp.2017.06.004.

3. Bassani R, Pereira GKR, Page MJ, et al. Systematic reviews in dentistry: current status, epidemiological and reporting characteristics. J Dent 2019;82:71-84. DOI: 10.1016/j.jdent.2019.01.014.

4. Elangovan S, Avila-Ortiz G, Johnson GK, et al. Quality assessment of systematic reviews on periodontal regeneration in humans. J Periodontol 2012;84(2):176-185. DOI: 10.1902/jop.2012.120021.

5. Mittal N, Goyal M, Sardana D, et al. Outcomes of surgical management of TMJ ankylosis: a systematic review and meta-analysis. J CranioMaxillofac Surg 2019;47(7):1120-1133. DOI: 10.1016/j.jcms.2019.03.029.

6. Kaban LB, Perrott DH, Fisher K. A protocol for management of temporomandibular joint ankylosis. J Oral Maxillofac Surg 1990;48(11):1145-1151. DOI: 10.1016/0278-2391(90)90529-B.

7. Kaban LB. A protocol for management of temporomandibular joint ankylosis in children. YJOMS 2009;67(9):1966-1978. DOI: 10.1016/ j.joms.2009.03.071.

8. Reporting guidelines|The EQUATOR Network n.d. Available at http:// www.equator-network.org/reporting-guidelines/. Accessed May 27, 2019.

9. Shea BJ, Grimshaw JM, Wells GA, et al. Development of AMSTAR: a measurement tool to assess the methodological quality of systematic reviews. BMC Med Res Methodol 2007;7:10. DOI: 10.1186/1471-22887-10.

10. Glenny AM, Esposito M, Coulthard P, et al. The assessment of systematic reviews in dentistry. Eur J Oral Sci 2003;111(2):85-92. DOl: 10.1034/j.1600-0722.2003.00013.x.

11. Oxman $A D$, Guyatt $G H$. Validation of an index of the quality of review articles. J Clin Epidemiol 1991;44(11):1271-1278. DOI: 10.1016/08954356(91)90160-B.

12. Oxman $A D$, Guyatt $G H$, Singer J, et al. Agreement among reviewers of review articles. J Clin Epidemiol 1991;44(1):91-98. DOI: 10.1016/08954356(91)90205-N.

13. Österberg $M$, Holmlund $A$, Sunzel $B$, et al. Knowledge gaps in oral and maxillofacial surgery: a systematic mapping. Int J Technol Assess Health Care 2017;33(1):93-102. DOI: 10.1017/S026646231700023X.

14. Sporniak-Tutak K, Janiszewska-Olszowska J, Kowalczyk R. Management of temporomandibular ankylosis - compromise or individualization - a literature review 2011;17(5):111-116.

15. Movahed R, Mercuri LG. Management of temporomandibular joint ankylosis. Oral Maxillofac Surg Clin North Am 2015;27(1):27-35. DOI: 10.1016/j.coms.2014.09.003

16. Sharma R, Manikandhan R, Sneha P, et al. Neocondyle distraction osteogenesis in the management of temporomandibular joint ankylosis: report of five cases with review of literature. Indian J Dent Res 2017;28(3):269-274. DOI: 10.4103/ijdr.IJDR_292_13.

17. Bénateau H, Chatellier A, Caillot A, et al. [Temporo-mandibular ankylosis]. Rev Stomatol Chir Maxillofac Chir Orale 2016;117(4): 245-255. DOI: 10.1016/j.revsto.2016.07.001.

18. American Association of Oral and Maxillofacial Surgeons. Temporomandibular joint surgery, parameters of care: clinical Practice guidelines for oral and maxillofacial surgery (AAOMS ParCare 2012). J Oral Maxillofac Surg 2012;70(Suppliment 3):e204-e231.

19. Katsnelson A. Operative management of temporomandibular joint ankylosis: a systematic review and meta-analysis. YJOMS 2012;70(3):531-536. DOI: 10.1016/j.joms.2011.10.003.

20. Balaji SM. Modified temporalis anchorage in craniomandibular reankylosis. Int J Oral Maxillofac Surg 2003;32(5):480-485. DOI: 10.1016/S0901-5027(03)90396-6.

21. Manganello-Souza LC, Mariani PB. Temporomandibular joint ankylosis: report of 14 cases. Int J Oral Maxillofac Surg 2003;32(1): 24-29. DOI: 10.1054/ijom.2002.0308.
22. Qudah MA, Qudeimat MA, Al-Maaita J. Treatment of TMJ ankylosis in Jordanian children-a comparison of two surgical techniques. J Craniomaxillofac Surg 2005;33(1):30-36. DOI: 10.1016/ j.jcms.2004.07.005.

23. Tanrikulu R, Erol B, Görgün B, et al. The contribution to success of various methods of treatment of temporomandibular joint ankylosis (a statistical study containing 24 cases). Turk J Pediatr 2005;47(3): 261-265.

24. Al-Moraissi EA, El-Sharkawy TM, Mounair RM, et al. A systematic review and meta-analysis of the clinical outcomes for various surgical modalities in the management of temporomandibular joint ankylosis. Int J Oral Maxillofac Surg 2015;44(4):470-482. DOI: 10.1016/j.ijom.2014.10.017.

25. Saeed N, Hensher R, McLeod N, et al. Reconstruction of the Temporomandibular joint autogenous compared with alloplastic. Br J Oral Maxillofac Surg 2002;40(4):296-299. DOI: 10.1016/S02664356(02)00139-0.

26. Ramezanian M, Yavary T. Comparison of gap arthroplasty and interpositional gap arthroplasty on the temporomandibular joint ankylosis. Acta Med Iran 2006;44(6):391-394.

27. Vasconcelos BC, Porto GG, Bessa-Nogueira RV, et al. Surgical treatment of temporomandibular joint ankylosis: follow-up of 15 cases and literature review. Med Oral Patol Oral Cir Bucal 2009;14(1):E34-E38.

28. Danda AK, Ramkumar S, Chinnaswami R. Comparison of gap arthroplasty with and without a temporalis muscle flap for the treatment of ankylosis. J Oral Maxillofac Surg 2009;67(7):1425-1431. DOI: 10.1016/j.joms.2008.12.049.

29. Tang W, Long J, Feng F, et al. Condyle replacement after tumor resection: comparison of individual prefabricated titanium implants and costochondral grafts. Oral Surg Oral Med Oral Pathol Oral Radiol Endod 2009;108(2):147-152. DOI: 10.1016/j.tripleo.2009.01.028.

30. Zhi K, Ren W, Zhou H, et al. Management of temporomandibular joint ankylosis: 11 years' clinical experience. Oral Surg Oral Med Oral Pathol Oral Radiol Endod 2009;108(5):687-692. DOI: 10.1016/ j.tripleo.2009.06.041.

31. Elgazzar RF, Abdelhady Al, Saad KA, et al. Treatment modalities of TMJ ankylosis: experience in delta Nile, Egypt. Int J Oral Maxillofac Surg 2010;39(4):333-342. DOI: 10.1016/j.ijom.2010.01.005.

32. Loveless TP, Bjornland T, Dodson TB, et al. Efficacy of temporomandibular joint ankylosis surgical treatment. J Oral Maxillofac Surg 2010;68(6):1276-1282. DOI: 10.1016/j.joms.2009.10.014.

33. Mansoor N, Khan M, Mehboob B, et al. Gap vs interpositional arthroplasty in the management of temporomandibular joint ankylosis. Pakistan Oral Dental J 2013;33:8-12.

34. Shaikh SK, Mishra M, Tiwari AK, et al. Comparative evaluation of gap arthroplasty and interpositional arthroplasty using temporalis fascia in the management of temporomandibular joint ankylosis. J Orofac Res 2013;3(3):170-174.

35. Mabongo M. Temporomandibular joint ankylosis in children. IOSRJDMS 2013;12(5):35-41. DOI: 10.9790/0853-1253541.

36. Holmlund A, Lund B, Weiner CK. Mandibular condylectomy with osteoarthrectomy with and without transfer of the temporalis muscle. Br J Oral Maxillofac Surg 2013;51(3):206-210. DOI: 10.1016/ j.bjoms.2012.05.011.

37. Ma J, Jiang $\mathrm{H}$, Liang L. Interpositional arthroplasty versus reconstruction arthroplasty for temporomandibular joint ankylosis: a systematic review and meta-analysis. J Cranio-Maxillofac Surg 2015;43(7):1202-1207. DOI: 10.1016/j.jcms.2015.04.017.

38. Ma J, Liang $L$, Jiang $H$, et al. Gap arthroplasty versus interpositional arthroplasty for temporomandibular joint ankylosis: a metaanalysis. PLoS ONE 2015;10(5):e0127652. DOI: 10.1371/journal.pone. 0127652.

39. Hu T, Li Z, Yu Y, et al. Clinical study of surgical treatment of ankylosis of temporomandibular joint. Zhonghua Zheng Xing Wai Ke Za Zhi 2005;21(6):408-411.

40. Erol B, Tanrikulu R, Görgün B. A clinical study on ankylosis of the Temporomandibular joint. J Craniomaxillofac Surg 2006;34(2): 100-106. DOI: 10.1016/j.jcms.2005.07.008. 
41. De Roo N, Van Doorne L, Troch A, et al. Quantifying the outcome of surgical treatment of temporomandibular joint ankylosis: a systematic review and meta-analysis. J Cranio-Maxillofac Surg 2016;44(1):6-15. DOI: 10.1016/j.jcms.2015.08.019.

42. Rajgopal A, Banerji PK, Batura V, et al. Temporomandibular ankylosis. A report of 15 cases. J Maxillofac Surg 1983;11(1):37-41. DOI: 10.1016/ S0301-0503(83)80009-5.

43. Chossegros C, Guyot L, Cheynet F, et al. Comparison of different materials for interposition arthroplasty in treatment of Temporomandibular joint ankylosis surgery: long-term follow-up in 25 cases. Br J Oral Maxillofac Surg 1997;35(3):157-160. DOI: 10.1016/ S0266-4356(97)90554-4.

44. Karaca C, Barutcu A, Menderes A. Inverted, T-shaped silicone implant for the treatment of temporomandibular joint ankylosis. J Craniofac Surg 1998;9(6):539-542. DOI: 10.1097/00001665-199811000-00009.

45. Chossegros C, Guyot L, Cheynet F, et al. Full-thickness skin graft interposition after temporomandibular joint ankylosis surgery. A study of 31 cases. Int J Oral Maxillofac Surg 1999;28(5):330-334. DOI: 10.1016/S0901-5027(99)80075-7.

46. Roychoudhury A, Parkash H, Trikha A. Functional restoration by gap arthroplasty in temporomandibular joint ankylosis: a report of 50 cases. Oral Surg Oral Med Oral Pathol Oral Radiol Endod 1999;87(2):166-169. DOI: 10.1016/S1079-2104(99)70267-2.

47. Erdem E, Alkan A. The use of acrylic marbles for interposition arthroplasty in the treatment of temporomandibular joint ankylosis: follow-up of 47 cases. Int J Oral Maxillofac Surg 2001;30(1):32-36. DOI: 10.1054/ijom.2000.0006.

48. Valentini V, Vetrano S, Agrillo A, et al. Surgical treatment of TMJ ankylosis: our experience (60 cases). J Craniofac Surg 2002;13(1):59-67. DOI: 10.1097/00001665-200201000-00013.

49. Güven O. Treatment of temporomandibular joint ankylosis by a modified fossa prosthesis. J Craniomaxillofac Surg 2004;32(4):236242. DOI: 10.1016/j.jcms.2004.02.004.

50. Dimitroulis G. The interpositional dermis-fat graft in the management of temporomandibular joint ankylosis. Int J Oral Maxillofac Surg 2004;33(8):755-760. DOI: 10.1016/j.ijom.2004.01.012.

51. Li Z-B, Li Z, Shang Z-J, et al. Potential role of disc repositioning in preventing postsurgical recurrence of traumatogenic temporomandibular joint ankylosis: a retrospective review of 17 consecutive cases. Int J Oral Maxillofac Surg 2006;35(3):219-223. DOI: 10.1016/j.ijom.2005.06.021.

52. Huang I-Y, Lai S-T, Shen Y-H, et al. Interpositional arthroplasty using autogenous costal cartilage graft for temporomandibular joint ankylosis in adults. Int J Oral Maxillofac Surg 2007;36(10):909-915. DOI: 10.1016/j.ijom.2007.05.009.

53. Güven O. A clinical study on temporomandibular joint ankylosis in children. J Craniofac Surg 2008;19(5):1263-1269. DOI: 10.1097/ SCS.0b013e3181577b1b.

54. El-Sayed KM. Temporomandibular joint reconstruction with costochondral graft using modified approach. Int J Oral Maxillofac Surg 2008;37(10):897-902. DOI: 10.1016/j.ijom.2008.07.023.

55. Krishnan B. Autogenous auricular cartilage graft in temporomandibular joint ankylosis-an evaluation. Oral Maxillofac Surg 2008;12(4):189193. DOI: 10.1007/s10006-008-0136-2.

56. Mehrotra D, Pradhan R, Mohammad S, et al. Random control trial of dermis-fat graft and interposition of temporalis fascia in the management of temporomandibular ankylosis in children. Br J Oral Maxillofac Surg 2008;46(7):521-526. DOI: 10.1016/j. bjoms.2008.03.002.

57. Bayat M, Badri A, Moharamnejad N. Treatment of temporomandibular joint ankylosis: gap and interpositional arthroplasty with temporalis muscle flap. Oral Maxillofac Surg 2009;13(4):207-212. DOI: 10.1007/ s10006-009-0174-4.

58. Yazdani J, Ghavimi MA, Pourshahidi S, et al. Comparison of clinical efficacy of temporalis myofascial flap and dermal graft as interpositional material in treatment of temporomandibular joint ankylosis. J Craniofac Surg 2010;21(4):1218-1220. DOI: 10.1097/ SCS.0b013e3181e1b4f6.
59. Liu Y, Li J, Hu J, et al. Autogenous coronoid process pedicled on temporal muscle grafts for reconstruction of the mandible condylar in patients with temporomandibular joint ankylosis. Oral Surg Oral Med Oral Pathol Oral Radiol Endod 2010;109(2):203-210. DOI: 10.1016/j.tripleo.2009.09.006.

60. Singh V, Dhingra R. Retrospective analysis of use of buccal fat pad as an Interpositional graft in Temporomandibular joint ankylosis. YJOMS 2011;69(10):2530-2536. DOI: 10.1016/j.joms.2011.02.022.

61. Singh V, Verma A, Kumar I, et al. Reconstruction of ankylosed temporomandibular joint: sternoclavicular grafting as an approach to management. Int J Oral Maxillofac Surg 2011;40(3):260-265. DOI: 10.1016/j.ijom.2010.09.023.

62. Yang X, Hu J, Yin G, et al. Computer-assisted condylar reconstruction in bilateral ankylosis of the temporomandibular joint using autogenous coronoid process. Br J Oral Maxillofac Surg 2011;49(8):612-617. DOI: 10.1016/j.bjoms.2010.10.015.

63. Gaba S, Sharma RK, Rattan V, et al. The long-term fate of pedicled buccal pad fat used for interpositional arthroplasty in TMJ ankylosis. J Plast Reconstr Aesthet Surg 2012;65(11):1468-1473. DOI: 10.1016/ j.bjps.2012.05.016.

64. Mehrotra D, Kumar S, Dhasmana S. Hydroxyapatite/collagen block with platelet rich plasma in temporomandibular joint ankylosis: a pilot study in children and adolescents. Br J Oral Maxillofac Surg 2012;50(8):774-778. DOI: 10.1016/j.bjoms.2012.01.002.

65. Nitzan DW, Abu Tair J, Lehman H. Is entire removal of a post-traumatic temporomandibular joint ankylotic site necessary for an optimal outcome? J Oral Maxillofac Surg 2012;70(12):e683-e699. DOI: 10.1016/j.joms.2012.08.007.

66. Sahoo NK, Tomar K, Kumar A, et al. Selecting reconstruction option for TMJ ankylosis: a surgeon's dilemma. J Craniofac Surg 2012;23(6):17961801. DOI: 10.1097/SCS.0b013e318270fab5.

67. Singh V, Dhingra R, Bhagol A. Prospective analysis of temporomandibular joint reconstruction in ankylosis with sternoclavicular graft and buccal fat pad lining. J Oral Maxillofac Surg 2012;70(4):997-1006. DOI: 10.1016/j.joms.2011.02.129.

68. Babu L, Kumar M, Ramesh C, et al. Is aggressive gap arthroplasty essential in the management of temporomandibular joint ankylosis? - a prospective clinical study of 15 cases. British J Oral Maxillofac Surg 2013;51(6):473-478. DOI: 10.1016/j.bjoms.2012.11.004.

69. Jakhar SK, Agarwal M, Gupta DK, et al. Preservation of condyle and disc in the surgical treatment of type III Temporomandibular joint ankylosis: a long-term follow-up clinical study of 111 joints. Int J Oral Maxillofac Surg 2013;42(6):746-751. DOI: 10.1016/j.ijom.2013. 02.002 .

70. Karamese M, Duymaz A, Seyhan N, et al. Management of temporomandibular joint ankylosis with temporalis fascia flap and fat graft. J Cranio-Maxillofac Surg 2013;41(8):789-793. DOI: 10.1016/ j.jcms.2013.01.027.

71. Zhu S, Wang D, Yin Q, et al. Treatment guidelines for temporomandibular joint ankylosis with secondary dentofacial deformities in adults. J Cranio-Maxillofac Surg 2013;41(7):e117-e127. DOI: 10.1016/j.jcms.2012.11.038.

72. Bhatt K, Roychoudhury A, Bhutia O, et al. Functional outcomes of gap and interposition arthroplasty in the treatment of temporomandibular joint ankylosis. J Oral Maxillofac Surg 2014;72(12):2434-2439. DOI: 10.1016/j.joms.2014.08.012.

73. Singh $V$, Bhagol A, DhingraR, etal.Management of Temporomandibular joint ankylosis type III: lateral arthroplasty as a treatment of choice. Int J Oral Maxillofac Surg 2014;43(4):460-464. DOI: 10.1016/ j.ijom.2013.08.013.

74. Kummoona R. Temporomandibular joint reconstruction with a 2-part chrome-cobalt prosthesis, chondro-osseous graft, and silastic: clinical and experimental studies. J Craniofac Surg 2009;20(6):2125-2135. DOI: 10.1097/SCS.0b013e3181bec688.

75. Kumar D, Rajan G, Raman U, et al. Autogenous reconstructive modalities of TMJ ankylosis-a retrospective analysis of 45 Cases. J Maxillofac Oral Surg 2014;13(4):359-365. DOI: 10.1007/s12663-0130504-9. 
76. Ahmad I, Mir MA, Bariar LM. Modified T-plate Interpositional arthroplasty for temporomandibular joint ankylosis: a new and versatile option. Arch Plast Surg 2015;42(6):716-720. DOI: 10.5999/ aps.2015.42.6.716.

77. Bhardwaj Y, Arya S. Post-Ankylotic temporomandibular joint reconstruction using autogenous/alloplastic materials: our protocol and treatment outcomes in 22 patients. Craniomaxillofac Trauma Reconstr 2016;9(4):284-293. DOI: 10.1055/s-0036-1584396.

78. Denadai R, Raposo-Amaral CE, Buzzo CL, et al. Matthews device arthroplasty presents superior long-term mouth opening than interpositional arthroplasty in the management of temporomandibular joint ankylosis. J Plas Recon Aesthe Surg 2016;69(8): 1052-1058. DOI: 10.1016/j.bjps.2016.04.001.

79. Shakeel M, Imran M, Ahad B, et al. Surgical treatment of temporomandibular joint ankylosis: skims experience of 105 cases. Int J Med Res Health Sci nd 5(6):77-82.

80. Dad F, Uppal A. Arthroplasty of temporomandibular joint ankylosi by autogenious tissue versus alloplastic material. Medical Forum Monthly 2017;28:85-88.

81. Xu F, Jiang L, Man C. A comparative study of different surgical methods in the treatment of traumatic temporomandibular joint ankylosis. Int J Oral Maxillofac Surg 2017;46(2):198-203. DOI: 10.1016/ j.ijom.2016.08.020.
82. Jiang $Y$, Huang $Y, Y e ~ B$, et al. Management of temporomandibular joint ankylosis with dentofacial deformities in children. J Craniofac Surg 2018;29(2):e150-e155. DOI: 10.1097/ SCS.0000000000004253.

83. Saltaji H, Ospina MB, Armijo-Olivo S, et al. Evaluation of risk of bias assessment of trials in systematic reviews of oral health interventions, 1991-2014: a methodology study. J Am Dent Assoc 2016;147(9): 720-728.e1. DOI: 10.1016/j.adaj.2016.03.017.

84. ICMJE. Recommendations for the Conduct, Reporting, Editing, and Publication of Scholarly Work in Medical Journals n.d.

85. Suebnukarn S, Ngamboonsirisingh S, Rattanabanlang A. A systematic evaluation of the quality of meta-analyses in endodontics. J Endod 2010;36(4):602-608. DOI: 10.1016/j.joen.2009.12.019.

86. Sacks HS, Berrier J, Reitman D, et al. Meta-analyses of randomized controlled trials. N Engl J Med 1987;316(8):450-455. DOI: 10.1056/ NEJM198702193160806.

87. Oxman AD. Checklists for review articles. BMJ 1994;309(6955): 648-651. DOI: 10.1136/bmj.309.6955.648.

88. Egger M, Smith GD, Altman DG. Assessing the quality of reports of systematic reviews: the QUOROM statement compared to other tools. Systematic Reviews in Health Care: Meta-analysis in context, 2nd ed. London: BMJ books; 2001. pp. 122-139. 
Table S1: Search methods performed in PubMed to retrieve the suitable data for assessment with search results obtained for evaluation

Search

First search

Second search

Third search

Fourth search
The methodology of search and use of various Boolean operators and $\mathrm{MeSH}$ terms

("ankylosis"[MeSH Terms] OR "ankylosis"[All Fields])

AND (("surgical procedures, operative"[MeSH Terms] OR ("surgical"[All Fields] AND "procedures"[All Fields] AND "operative"[All Fields]) OR "operative surgical procedures"[All Fields] OR "surgical"[All Fields]) AND ("organization and administration"[MeSH Terms] OR ("organization"[All Fields] AND "administration"[All Fields]) OR "organization and administration"[All Fields] OR "management"[All Fields] OR "disease management"[MeSH Terms] OR ("disease"[All Fields] AND "management"[All Fields]) OR "disease management"[All Fields])) AND (Review[ptyp] AND ("1980/01/01"[PDAT]: "2018/12/31"[PDAT]) AND"humans"[MeSH Terms])

("Temporomandibular ankylosis"[Supplementary Concept] OR "Temporomandibular ankylosis"[All Fields] OR "temporomandibular ankylosis"[All Fields]) AND (("surgical procedures, operative"[MeSH Terms] OR ("surgical"[All Fields] AND "procedures"[All Fields] AND "operative"[All Fields]) OR "operative surgical procedures"[All Fields] OR "surgical"[All Fields]) AND ("organization and administration"[MeSH Terms] OR ("organization"[All Fields] AND "administration"[All Fields]) OR "organization and administration"[All Fields] OR "management"[All Fields] OR "disease management"[MeSH Terms] OR ("disease"[All Fields] AND "management"[All Fields]) OR "disease management"[All Fields])) AND (Review[ptyp] AND ("1980/01/01"[PDAT]: "2018/12/31"[PDAT]) AND “humans"[MeSH Terms])

(("Temporomandibular ankylosis"[Supplementary Concept] OR "Temporomandibular ankylosis"[All Fields] OR "temporomandibular ankylosis"[All Fields]) AND ("organization and administration"[MeSH Terms] OR ("organization"[All Fields] AND "administration"[All Fields]) OR "organization and administration"[All Fields] OR "management"[All Fields] OR "disease management"[MeSH Terms] OR ("disease"[All Fields] AND "management"[All Fields]) OR "disease management"[All Fields])) AND (Review[ptyp] AND ("1980/01/01"[PDAT]: "2018/12/31"[PDAT]) AND "humans"[MeSH Terms])

("Temporomandibular ankylosis"[Supplementary Concept] OR "Temporomandibular ankylosis"[All Fields] OR "temporomandibular ankylosis"[All Fields]) AND ((“1980/01/01"[PDAT]: "2018/12/31"[PDAT]) AND "humans"[MeSH Terms])
Description of search criteria and results obtained

The results obtained with the following filters activated: Review, Publication date from 1980/01/01 to 2018/12/31, Humans; the search team found total of 5 publications out of 615 items

The results obtained with following filters activated: Review, Publication date from 1980/01/01 to 2018/12/31, Humans; the search team found 5 publications out of 46 items

The results obtained with the following filters activated: Publication date from 1980/01/01 to 2018/12/31, Humans; the search team found 164 out of 231 items. Further activation of Filter: Review, resulted in 11 publications

The results obtained with the following filters activated: Review, Publication date from 1980/01/01 to $2018 / 12 / 31$, Humans; the search team found 85 publications out of 615 items 


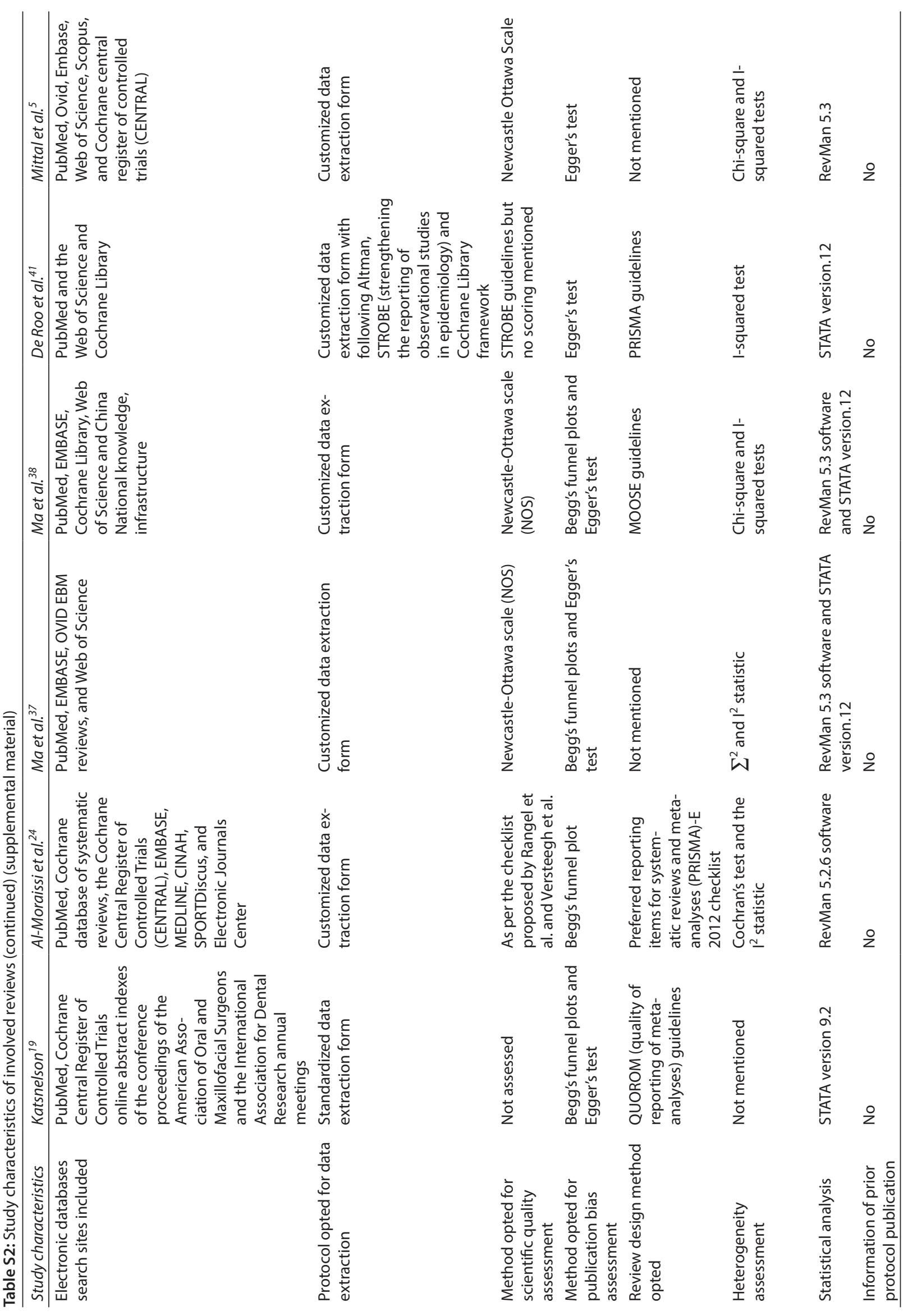


Table S3: Study details extracted from the MA selected for critical analysis (supplemental material)

\begin{tabular}{|c|c|c|c|c|c|}
\hline S. no. & Author and year & $\begin{array}{l}\text { No. of patients } \\
\text { included }\end{array}$ & Data search timeline & $\begin{array}{l}\text { Investigator and year } \\
\text { of publication }\end{array}$ & Type of study \\
\hline \multirow[t]{4}{*}{1} & Katsnelson ${ }^{19}(2012)$ & $\begin{array}{l}52 \text { patients in one } \\
\text { group and } 39 \text { patients } \\
\text { in another group }\end{array}$ & $\begin{array}{l}\text { January } 1966 \text { through } \\
\text { May } 2010\end{array}$ & Manganello, 2003 & Not mentioned \\
\hline & & & & Balaji, 2003 & Not mentioned \\
\hline & & & & Qudah et al., 2005 & Not mentioned \\
\hline & & & & Tanrikulu et al., 2005 & Not mentioned \\
\hline \multirow[t]{16}{*}{2} & $\begin{array}{l}\text { Al-Moraissi et al. }{ }^{24} \\
(2014)\end{array}$ & & & Saeed et al. 2002 & Retrospective study \\
\hline & & & & Balaji, 2003 & Control clinical trial \\
\hline & & & & Manganello, 2003 & Control clinical trial \\
\hline & & & & Tanrikulu et al., 2005 & Retrospective study \\
\hline & & & & Qudah et al., 2005 & Retrospective study \\
\hline & & & & $\begin{array}{l}\text { Ramezanian and } \\
\text { Yavary et al., } 2006\end{array}$ & Control clinical trial \\
\hline & & & & $\begin{array}{l}\text { Vasconcelos et al., } \\
2009\end{array}$ & Retrospective study \\
\hline & & & & Danda et al., 2009 & Control clinical trial \\
\hline & & & & Tang et al., 2009 & Retrospective study \\
\hline & & & & Zhi et al., 2009 & Retrospective study \\
\hline & & & & Elgazzar et al. 2010 & Retrospective study \\
\hline & & & & Loveless et al., 2010 & Retrospective study \\
\hline & & & & Mansoor et al., 2013 & Control clinical trial \\
\hline & & & & Shaikh et al., 2013 & Control clinical trial \\
\hline & & & & Mabongo, 2013 & Retrospective study \\
\hline & & & & Holmlund et al., 2013 & Controlled clinical trail \\
\hline 3 & Ma et al. ${ }^{37}$ (2015) & $\begin{array}{l}\text { Reconstruction ar- } \\
\text { throplasty group } 106\end{array}$ & $\begin{array}{l}\text { No time restriction } \\
\text { search performed up }\end{array}$ & Balaji, 2003 & $\begin{array}{l}\text { Retrospective cohort } \\
\text { study }\end{array}$ \\
\hline
\end{tabular}

and Interposition ar- to October 11, 2014

throplasty 92 patients

among 6 studies
Manganello, $2003 \quad$ Retrospective cohort study

Tanrikulu, $2005 \quad$ Retrospective cohort study

Qudah, $2005 \quad$ Retrospective cohort study

Total of 272 patients From 1946 to July 28, Hu, 2005 among eight studies 2014 divided into two groups

Retrospective cohort

Retrospective cohort
Erol, 2006

Loveless, 2010

Elgazzar, 2010

Sahoo, 2012

Retrospective cohort study study study

Retrospective cohort study

Retrospective cohort study

Tanrikulu, 2005

Erol, 2006

Ramezanian, 2006
Retrospective cohort study

Retrospective cohort study

Retrospective cohort study 
Contd...

\begin{tabular}{|c|c|c|c|c|c|}
\hline S. no. & Author and year & $\begin{array}{l}\text { No. of patients } \\
\text { included }\end{array}$ & Data search timeline & $\begin{array}{l}\text { Investigator and year } \\
\text { of publication }\end{array}$ & Type of study \\
\hline & & & & Danda, 2009 & $\begin{array}{l}\text { Retrospective cohort } \\
\text { study }\end{array}$ \\
\hline & & & & Zhi, 2009 & $\begin{array}{l}\text { Retrospective cohort } \\
\text { study }\end{array}$ \\
\hline & & & & Elgazzar, 2010 & $\begin{array}{l}\text { Retrospective cohort } \\
\text { study }\end{array}$ \\
\hline & & & & Holmlund, 2013 & $\begin{array}{l}\text { Retrospective cohort } \\
\text { study }\end{array}$ \\
\hline \multirow[t]{35}{*}{5} & De Roo et al..$^{41}$ (2015) & $\begin{array}{l}\text { Total of } 1,165 \text { patients } \\
\text { among } 36 \text { studies fur- } \\
\text { ther divided into five } \\
\text { groups consisting of } \\
\text { GA-463, IA auto-341, } \\
\text { IA allo-68, RA auto- } \\
260 \text {, and RA allo-33 }\end{array}$ & $\begin{array}{l}\text { Up to October 11, } \\
2014\end{array}$ & Rajgopal, et al., 1983 & Not mentioned \\
\hline & & & & $\begin{array}{l}\text { Chossegros et al., } \\
1997\end{array}$ & Not mentioned \\
\hline & & & & Karaca et al., 1998 & Not mentioned \\
\hline & & & & $\begin{array}{l}\text { Chossegros et al., } \\
1999\end{array}$ & Not mentioned \\
\hline & & & & $\begin{array}{l}\text { Roychoudhury et al., } \\
1999\end{array}$ & Not mentioned \\
\hline & & & & $\begin{array}{l}\text { Erdem and Alkan, } \\
2001\end{array}$ & Not mentioned \\
\hline & & & & Valentini et al., 2002 & Not mentioned \\
\hline & & & & Manganello, 2003 & Not mentioned \\
\hline & & & & Guven, 2004 & Not mentioned \\
\hline & & & & Dimitroulis, 2004 & Not mentioned \\
\hline & & & & Qudah et al., 2005 & Not mentioned \\
\hline & & & & Tanrikulu et al., 2005 & Not mentioned \\
\hline & & & & Li et al., 2006 & Not mentioned \\
\hline & & & & Huang et al., 2007 & Not mentioned \\
\hline & & & & Guven, 2008 & Not mentioned \\
\hline & & & & El-Sayed, 2008 & Not mentioned \\
\hline & & & & Krishnan, 2008 & Not mentioned \\
\hline & & & & Mehrotra et al., 2008 & Not mentioned \\
\hline & & & & Bayat et al., 2009 & Not mentioned \\
\hline & & & & Danda et al., 2009 & Not mentioned \\
\hline & & & & Yazdani et al., 2010 & Prospective study \\
\hline & & & & Liu et al., 2010 & Not mentioned \\
\hline & & & & Elgazzar et al., 2010 & Not mentioned \\
\hline & & & & Liu et al., 2011 & Not mentioned \\
\hline & & & & Singh et al., 2011a & Not mentioned \\
\hline & & & & Singh et al., $2011 \mathrm{~b}$ & Not mentioned \\
\hline & & & & Yang et al., 2011 & Not mentioned \\
\hline & & & & Gaba et al., 2012 & Prospective study \\
\hline & & & & Mehrotra et al., 2012 & $\begin{array}{l}\text { Randomized con- } \\
\text { trolled trial }\end{array}$ \\
\hline & & & & Nitzan et al., 2012 & Not mentioned \\
\hline & & & & Sahoo et al., 2012 & Not mentioned \\
\hline & & & & Singh et al., 2012 & Prospective study \\
\hline & & & & Babu et al., 2013 & Prospective study \\
\hline & & & & Jakhar et al., 2013 & Not mentioned \\
\hline & & & & & Contc \\
\hline 348 & \multicolumn{5}{|c|}{ The Journal of Contemporary Dental Practice, Volume 21 Issue 3 (March } \\
\hline
\end{tabular}


Contd...

\begin{tabular}{|c|c|c|c|c|c|}
\hline S. no. & Author and year & $\begin{array}{l}\text { No. of patients } \\
\text { included }\end{array}$ & Data search timeline & $\begin{array}{l}\text { Investigator and year } \\
\text { of publication }\end{array}$ & Type of study \\
\hline & & & & Karamese et al., 2013 & Not mentioned \\
\hline & & & & Zhu et al., 2013 & Not mentioned \\
\hline & & & & Bhatt et al., 2014 & Not mentioned \\
\hline & & & & Singh et al., 2014 & Not mentioned \\
\hline \multirow[t]{26}{*}{6} & Mittal et al. ${ }^{5}$ (2019) & $\begin{array}{l}\text { Total of 1,197 patients } \\
\text { among } 26 \text { studies. } \\
\text { Further divided into } \\
\text { groups }\end{array}$ & $\begin{array}{l}\text { Searched till April } \\
2018\end{array}$ & Valentini et al., 2002 & $\begin{array}{l}\text { Nonrandomized } \\
\text { controlled trial }\end{array}$ \\
\hline & & & & Balaji, 2003 & Retrospective study \\
\hline & & & & $\begin{array}{l}\text { Souza and Mariani, } \\
2003\end{array}$ & $\begin{array}{l}\text { Nonrandomized } \\
\text { controlled trial }\end{array}$ \\
\hline & & & & Hu et al., 2005 & Retrospective study \\
\hline & & & & Tanrikulu et al., 2005 & Retrospective study \\
\hline & & & & Qudah et al., 2005 & Retrospective study \\
\hline & & & & $\begin{array}{l}\text { Ramezanian and } \\
\text { Yavary, } 2006\end{array}$ & $\begin{array}{l}\text { Nonrandomized } \\
\text { controlled trial }\end{array}$ \\
\hline & & & & Erol et al., 2007 & Retrospective study \\
\hline & & & & Güven et al., 2008 & Retrospective study \\
\hline & & & & Danda et al., 2009 & $\begin{array}{l}\text { Nonrandomized } \\
\text { controlled trial }\end{array}$ \\
\hline & & & & $\begin{array}{l}\text { Kummoona et al., } \\
2009\end{array}$ & $\begin{array}{l}\text { Nonrandomized } \\
\text { controlled trial }\end{array}$ \\
\hline & & & & $\begin{array}{l}\text { Vasconcelos et al., } \\
2009\end{array}$ & Retrospective study \\
\hline & & & & Zhi et al., 2009 & Retrospective study \\
\hline & & & & Elgazzar et al., 2010 & Retrospective study \\
\hline & & & & Loveless et al., 2010 & Retrospective study \\
\hline & & & & Sahoo et al., 2012 & Retrospective study \\
\hline & & & & Shaikh et al., 2013 & $\begin{array}{l}\text { Nonrandomized } \\
\text { controlled trial }\end{array}$ \\
\hline & & & & Bhatt et al., 2014 & Retrospective study \\
\hline & & & & Kumar et al., 2014 & Retrospective study \\
\hline & & & & Ahmad et al., 2015 & $\begin{array}{l}\text { Nonrandomized } \\
\text { controlled trial }\end{array}$ \\
\hline & & & & $\begin{array}{l}\text { Bhardwaj and Arya, } \\
2016\end{array}$ & Retrospective study \\
\hline & & & & Denadai et al., 2016 & Retrospective study \\
\hline & & & & Shakeel et al., 2016 & Retrospective study \\
\hline & & & & Dad and Uppal, 2017 & Retrospective study \\
\hline & & & & Jiang et al., 2017 & Retrospective study \\
\hline & & & & Xu et al., 2017 & Retrospective study \\
\hline
\end{tabular}

Table S4: Spearman's rank correlation between AMSTAR and Glenny et al. scores

\begin{tabular}{lllll}
\hline & $n$ & Spearman $R$ & $t(\mathrm{~N}-2)$ & $p$-level \\
\hline $\begin{array}{l}\text { AMSTA and Glenny } \\
\text { et al. scores }\end{array}$ & 6 & 0.6642 & 1.7770 & 0.1502 \\
\hline
\end{tabular}

